\title{
Analysis of Change in Diversity Pattern Due to Environmental Change to Improve the Conservation of Species
}

\author{
Muhammad Ahmad Raza ${ }^{1}$, Sibghatullah Bazai², Zeyun Li ${ }^{3 *}$, Raja Asif Wagan², \\ Mir Muhammad Nizamani ${ }^{4}$, Aamir Ali Khokhar ${ }^{4}$ \\ ${ }^{1}$ College of Computer and Cyberspace Security, Hainan University, Haikou, 570228, P.R. China \\ ${ }^{2}$ Department of Information Technology, BUITEMS, Quetta, Pakistan \\ ${ }^{3}$ Geography Section, School of Humanities, Universiti Sains Malaysia, Penang, Malaysia \\ ${ }^{4}$ Key Laboratory of Tropical Biological Resources of Ministry of Education, College of Tropical Crops, \\ Hainan University, Haikou, China
}

Received: 23 June 2021

Accepted: 10 September 2021

\begin{abstract}
Plant communities in cities have obvious beautification and improvement effects on the environment, and at the same time are important places and open spaces for biodiversity conservation. With the acceleration of urbanization, the research and development of urban plant communities has become a trend of urban ecological construction, and making full use of trees is also an important guiding ideology in current urban greening in my country. Therefore, this article conducts a comparative analysis and research on the species diversity of different types of plant communities in the urban area Karachi. In Karachi, which is in the province of Sindh, Pakistan, roadside trees along various road types (e.g., wide, medium and narrow roads) have been studied. Field study has been conducted on different paths of the Karachi city to understand the diversity pattern of the species. A total of 150 plots, divided into 3 categories of roads which were surveyed. The highest quantity of tree biomass per unit area was found on wide roads, followed by medium roads. On narrow roads, the least biomass was detected. A single species or a limited number of species dominated the diversity of species. Conocarpus erectus was the most dominant non-native species along all types of roads, followed by the species Guaiacum officinale. A total of 76 species (32 non-native and 44 native) that were selectively spread along the roadsides of the city were studied. There was a significant difference in phylogenetic diversity (PD), phylogenetic mean pairwise distance (MPD) and phylogenetic mean nearest taxon distance (MNTD) between different types of roads. Our study identified patterns of diversity in roadside trees in Karachi.
\end{abstract}

Keywords: sidewalks diversity, tree diversity, diversity pattern, Pakistan

e-mail: lizeyun@yahoo.com 


\section{Introduction}

Urban forest is a component of urban ecosystem, and the ecosystem services it provides are closely related to the health and well-being of urban residents. The diversity of urban tree species is one of the key influencing factors for maintaining the stability of urban forests and facilitating the continuous provision of ecosystem services [1-3]. Although the improvement of urban tree species diversity can be achieved by increasing the number of tree species used in greening, practice has proved that improper tree species selection is not only difficult to produce good ecological benefits, but can also lead to economic losses and waste of resources. Therefore, a full understanding of the current status and driving factors of the diversity of urban tree species in many countries, and on this basis, propose a tree species planning plan to reasonably increase the diversity of tree species, which has important scientific and practical significance for the construction of urban forests $[4,5]$.

Urban forests can provide a variety of ecosystem services. They can fix carbon and release oxygen, reduce pollutants in the air and reduce noise [6]. According to estimates, the value of the ecosystem purification service function provided by the Changsha urban forest in one year can reach about 3.943 billion yuan. Urban forests can block direct sunlight and reduce air temperature, and provide a cool environment for urban residents in the hot summer. This cooling effect can also help alleviate the urban heat island effect. For example, the analysis of the environmental effects of Beijing's meteorological data from 1994 to 2003 shows that the Beijing urban heat island effect has a gradual increase from 1994 to 2003, but this trend is in Since the strengthening of urban greening in 1999, it has eased. These cooling effects on the environment can reduce urban residents' demand for air-conditioning, thereby reducing energy consumption and greenhouse gas emissions [7]. When encountering extreme rainfall, urban forests can also help alleviate the destructiveness of urban floods through interception and stagnation. Trees in urban forests can also absorb heavy metals in the soil (such as lead, cadmium, copper, etc.), and promote the restoration of urban soil environment. Urban forests also provide habitats and shelters for animals living in cities, as well as their main food sources, and play a key role in maintaining urban biodiversity [8]. The study also found that a well-grown urban forest has a positive effect on the biological response to climate change in urban areas, and the buffer provided by the forest can alleviate a series of negative effects caused by climate change. In addition to ecological functions, urban forests also have a variety of social and economic functions, the most widely known of which is the role of urban forests in beautifying the urban environment. In addition, urban forests can provide economic products such as wood, fruits and vegetables for the production and life of residents. It can also provide health, recreational opportunities and entertainment venues. Urban forests also have an important impact on the price of real estate. Houses located in wooded residential areas usually have a higher market value than houses in areas with poor green conditions, that is, higher tree coverage corresponds to higher property prices [9]. An analysis of the prices of 75 properties in Tennessee, USA from 2003 to 2005 showed that the impact of tree cover on property prices was about $30 \%$. In the analysis of the factors affecting housing prices in Chongqing, even after excluding villas and other high-end commercial houses, the greening rate is still an important factor affecting housing prices. Due to these ecological, social and economic values of urban forests, healthy and fully functional urban forests are unanimously considered as the material basis for sustainably maintaining a higher quality of life and well-being of residents.

Roadside tree planning in urban systems is playing a vital role since roadside trees act as local biodiversity reservoirs and reduce the pollution of the atmosphere by having a carbon stock. The roadside ecosystem has significant importance because of its involvement in the diversity patterns of the biological life. Various studies have concluded that the ecosystem along the roadside is novel and unique. Over the last few years, the construction of roads has increased significantly because of the economic growth of countries and the increase in urbanization, which causes new surfaces in different landscapes. [10] Therefore, the soil patterns along the roadside are gradually changing, resulting in a change in plants' diversity patterns. Roads and highways are an important infrastructure of the national economy, and the gradually increasing density of the highway network is the foundation for sustainable economic and social development. However, it has one major disadvantage also that continuous construction and maintenance of roads causes the abiotic conditions of the system to change the physical and chemical environment of the surrounding area [11].

The original topography and the continuity of the original structure have been altered due to the huge volume of urbanization and excavation, resulting in a variety of environmental issues, such as soil degradation, environmental contamination, habitat loss, and changes in the original river system, causing air pollution and noise pollution. The environmental role of road greening is reflected in the mitigation of the environmental effect of road building on the local area, such as dust collection and noise avoidance, air purification, water and soil protection, road temperature control, and biodiversity preservation along the road [12]. The greening of urban roads is designed according to the form of the road, and therefore it generally has linear characteristics. From this perspective, the greening of urban roads needs to be extended according to the actual needs of the road. Moreover, the planted varieties are diverse and have strong temporality. These varieties have different characteristics in different 
seasons. Therefore, the landscape of the entire city will also have seasonal changes, and the streetscape landscape effect is better [13].

The rise of cities led to the decline of plants. In today's cities, the original vegetation has disappeared, and the existing green vegetation is almost secondary. Due to the decline of the urban natural environment, the number of urban plants has decreased, and the diversity of species is extremely less [14]. The plants next to houses, roadsides, artificial gardens, and parks are mainly cultivated and introduced, while the number of wild plants and native tree species is greatly reduced. As a result of natural disasters and man-made destruction, the habitat of urban plants is smaller, and the threats they face are greater [15].

Simultaneously, the rise of cities has also caused the decline of wildlife. The survival of large animals relies on forests and wilderness. However, forests have disappeared around cities, and the wilderness is also occupied by humans, causing large animals to withdraw from urban areas. Modern urban animals include birds, urban insects, and livestock and poultry [16]. Due to the intensification of urbanization, the spatial heterogeneity of the urban environment has decreased, resulting in a decrease in the types of urban birds and a change in their composition, forming a relatively simple community of a few dominant species. These dominant species, such as house swallows, house martins, and sparrows, are only birds that utilize to artificially constructed nests [17]. Another study reveals the important fact that with the gradual decrease in urban biological species, leads to a decline in biodiversity.

Roadsides create new opportunities for the relationship between different species and, in some cases, are helpful in providing segmented ecosystems for different types of plants that have different growth patterns [18]. The age of the road provides significant information related to the plantation and habitat along the roadside. A study has indicated that the native species are mostly found along the roadside of the youngest roads, while invasive species are mostly found close to old roads. Only a few studies have focused on the temporal patterns of plant diversity along the roadside and the conditions of vegetation on these fragments. However, road age is not the only significant factor in the appearance of invasive species, as transportation is also a facilitator for the invasive species and causes them to spread out along the roadside. Many studies have concluded that the ecosystem damage and transfer of invasive species along the roadside is due to the transportation [19].

Different studies show the different impacts of the diversity pattern along roads on biological and environmental conditions. For example, species composition is directly impacted with the texture of the roads within a community [20]. Elevation also impact the growth of native and non native species, and results in change in richness of diversity as much elevation pattern changes in roadside. Roadside tree provide better climate effects which decrease urban thermal discomfort and heat-related human health issues [21, 22].

An in-depth or greater understanding of road effects can help manage the impacts of roads. With the continuous improvement of people's living standards, people have higher requirements for the environment. As an important part of urban infrastructure construction, the construction of urban roads has also received much attention. Moreover, to improve the quality of urban road construction, it is necessary to consider road landscape design and optimize plant species [23]. Only in this way can we effectively change the ecological environment of the city and create a wonderful visual experience for people's daily travel. Due to increasing importance and awareness, there is still less knowledge of roads diversity analysis in metropolitan city Karachi [24]. As mentioned above, many studies have focused on the diversity of roadside plants and animals; however, few studies have focused on the analysis of the patterns of diversity along the roadside [25] [26]. The deficiency of knowledge and the importance concerning roadside trees in Karachi influenced us to study the roadside diversity pattern of trees. This study focuses on the analysis of the biodiversity patterns along the roadside and highlights the changes in the diversity patterns of plants by assessing the assesses species richness, evenness and biomass of trees. In depth examine the diversity pattern, composition, tree density, and taxonomic diversity of the roadside tree community. This study highlights the significance of diversity patterns for the government for planning the roadside tree species [27].

\section{Material and Methods}

\section{Location Area}

Pakistan does have a tropical monsoon climate in terms of geographical divisions, but due to the large area of deserts in the country, the tropical desert climate is also very wide, but the overall climate is still tropical monsoon climate. Most parts of Pakistan are in the subtropical zone. Generally speaking, the climate in Pakistan is relatively hot and dry. The average annual rainfall is less than $250 \mathrm{~mm}$, and the rainfall in $1 / 4$ of the area is less than $120 \mathrm{~mm}$. The hottest season in Pakistan is June and July. The temperature at noon in most areas exceeds $40^{\circ} \mathrm{C}$, while in parts of Sindh and Balochistan, the temperature at noon may be as high as $50^{\circ} \mathrm{C}$. The northern mountainous area with an altitude of more than 2 kilometers is cooler, and the temperature difference is large, the average temperature difference between day and night is about $14^{\circ} \mathrm{C}$. The coldest season is from December to February. Pakistan is located in the subtropical zone. Except for the Baluchistan region, most of Pakistan has a tropical monsoon climate, which is similar to the temperate monsoon climate 


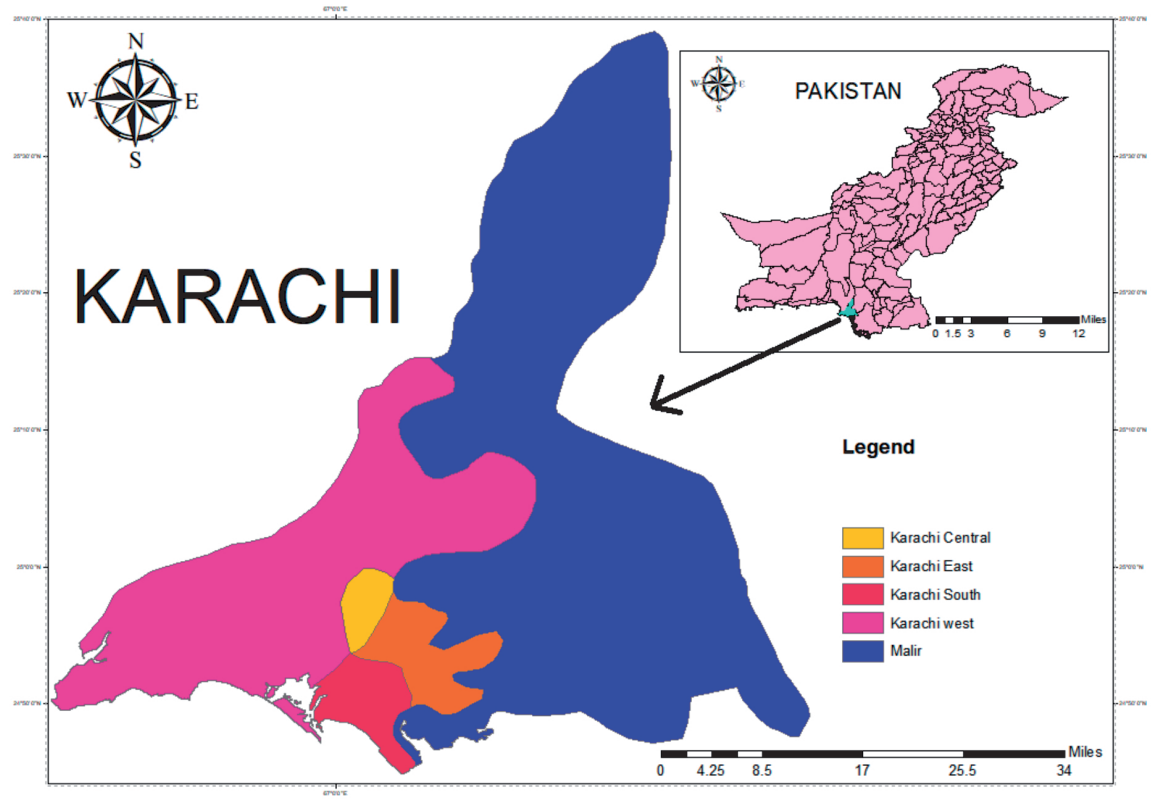

Fig. 1. Location of towns in Karachi.

in eastern my country, but its temperature is much higher than that in eastern my country. The coastal areas of Pakistan have high temperatures and small temperature differences [28]. The high mountainous areas in the northwest and the Baluchistan Plateau have variable climates and large temperature differences. Some high mountainous areas in the north even cover snow all the year round. The Baluchistan region has many mountains and deserts, and the climate is hot and dry. Pakistan's climate is customarily divided into four seasons: March-April is spring. The climate in these two months is not hot or cold, relatively mild, but dry; May-August is summer, of which June has the highest temperature, sometimes as high as $45^{\circ} \mathrm{C}$; July and August are rainy, so it is usually called the rainy season in July and August; September to October is autumn; November to February is winter, and the temperature of day and night in winter varies greatly. The temperature can reach $25^{\circ} \mathrm{C}$ during the day and sometimes at night, will drop to freezing point. We selected the metropolitan city Karachi, which is the most populous city in Pakistan and the sixth-largest city in the world. The reasons for selecting this city are the continuous development of roads and the implementation of new projects for underpasses under bridges. The weather of Karachi is warm in summer and moderate in winter. In the summer, the temperature is between $25^{\circ} \mathrm{C}$ and $35^{\circ} \mathrm{C}$, and there is average rainfall (Fig. 1). The winter is from the end of November to the beginning of February, and the daily average temperature is between $16^{\circ} \mathrm{C}$ and $21^{\circ} \mathrm{C}$. The winter is mostly dry, while the summer is mostly wet with high humidity. According to the 2020 world population survey, around 16 million people were living in the city, which covers an area of $3,580 \mathrm{~km}^{2}$ and the annual population increase is estimated to be $6 \%$. There are seven districts in Karachi (Central
District, East District, West District, Korangi District, South District, Malir District, and Kemari District). Some of the famous and long-distance roads are I. I. Chundrigar Road (2.2 km), M. A. Jinnah Road $(6.1 \mathrm{~km})$, Napier Road $(1.6 \mathrm{~km})$, Zaibunnisa Street $(1.1 \mathrm{~km})$, Shahrah-e-Faisal (18.0 km), Rashid Minhas Road (3.0 km),New Muhammad Ali Jinnah Road (6.1 km), and Nishtar Road $(5.6 \mathrm{~km})$. The different road routes across Karachi are shown in Fig. 2.

\section{Data Collection}

To examine the diversity pattern along the roads, categories of roads are divided into wide $(24 \mathrm{~m}$ or wider), medium (12 $\mathrm{m}$ to $24 \mathrm{~m}$ wide) and narrow (less than $12 \mathrm{~m}$ wide) roads. The large roads of Karachi are known as the main roads and are bigger in scale than other road types. The linking roads between these large roads are medium roads. Usually, narrow roads are narrower than these two types. Departments of urban management oversee all road types and are responsible for planting trees. However, the pathways are near homes on small roads, and local people are also responsible for planting and caring for trees.

We conducted the biodiversity surveys of tree pictures to verify tree species with the help of an expert. Our survey coverage areas were roadside tree of the Karachi. The sampling plots were chosen with the aid of Google Earth (https://www.google.com/earth/). One plot of each of $0.5 \mathrm{~km} \times 50$ length on every kilometer was made from one end of each street of every town for tree sampling. The streets of less than one kilometer were excluded from the study. The property line on both sides of the streets was taken as the width of each transect. On all types of roads, a total of 150 plots have been measured; each type of road has equivalent 


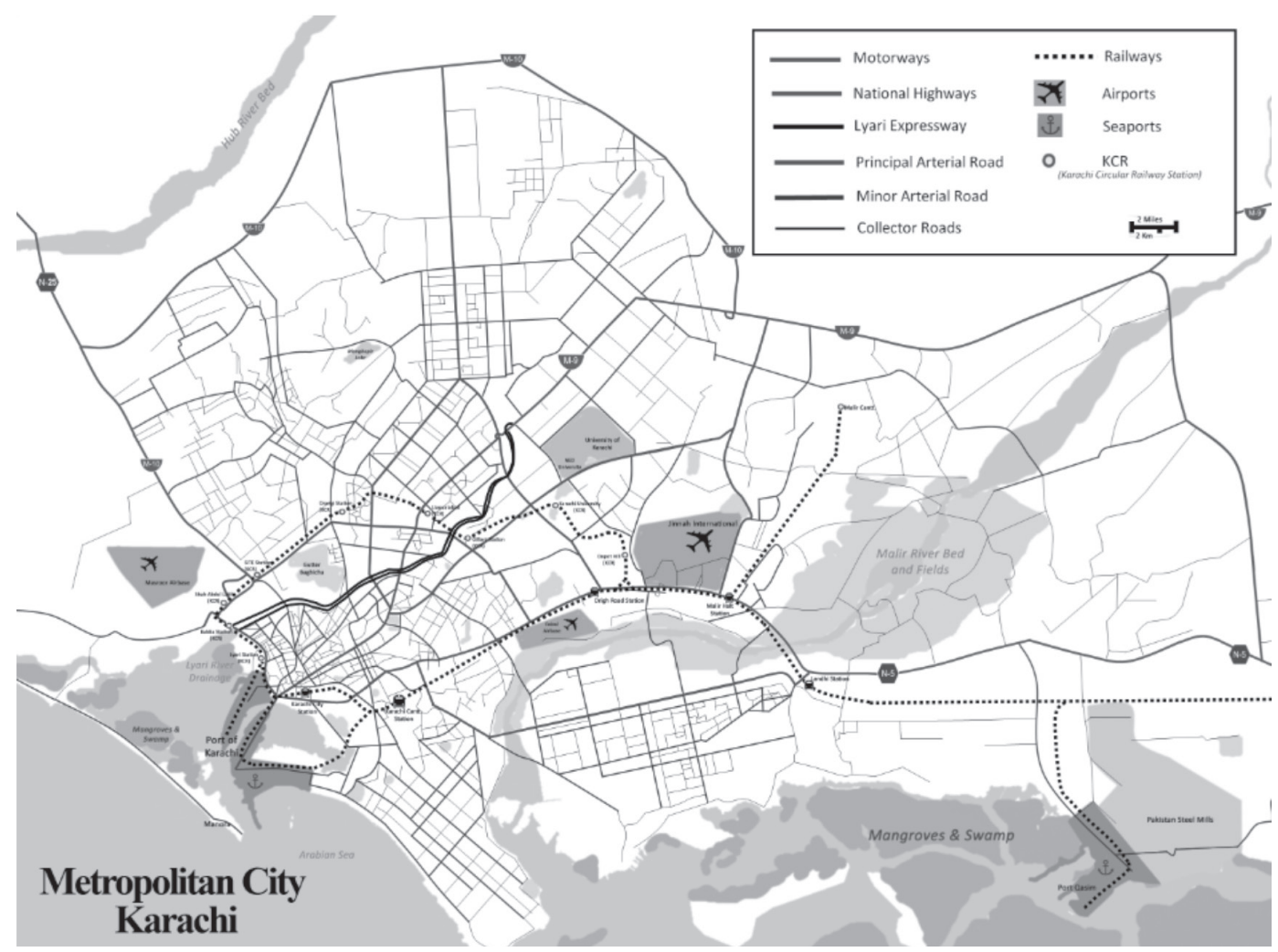

Fig. 2. Road map of Karachi.

parcels. The key details calculated at the point of sampling are the name of the species of the tree, the number of branches, the diameter $(\mathrm{cm})$, the height (cm), and the width of the crown of each roadside tree. The strength of the management of each type of road was ascertained in interviews with maintenance staff and, if possible, local people. Approximately 20 percent of the total roadside lengths of the city were sampled.

\section{Data Analysis}

\section{Species Diversity Data}

To identify the species diversity in the plant population, the plant species diversity index was used as the most simple and succinct attribute, and the stability index was used to assess ecosystem stability. Biodiversity can be quantified in many ways, and there are two major factors: richness (richness) and uniformity (evenness). Species richness does not consider conceptually how many individuals (in the sample) each species has. It gives the same weight to a species with a small number of individuals as a species with a large number of individuals. Species evenness refers to how close in numbers each species in an environment is. Diversity increases with the increase in species richness and uniformity. The Simpson Diversity Index considers both richness and uniformity. We used indices of species diversity from Simpson and Pielou (1966). The computational formulas are clarified below.
1. Richness of species (S) refers to the number of species of trees in each systemic urban unit.

2. The Simpson Diversity Index (D) corresponds to the possibility that two consecutive samples of a population that belong to the same species derive the corresponding number of individuals:

$$
\mathrm{D}=1-\sum_{i=1}^{n} P i^{2} P_{i}^{2}=\frac{\mathrm{n}_{i}\left(n_{i}-1\right)}{\mathrm{N}(\mathrm{N}-1)}
$$

This reflects the probability that two individuals are randomly selected from the same sample, and the two individuals are from the same class. The value of $\mathrm{N}$ is between 0 and 1 , where 0 means unlimited diversity, and 1 means no diversity; that is, the larger the $\mathrm{D}$ value, the lower the diversity.

3. Species evenness refers to how close in numbers each species in an environment is. Mathematically it is defined as a diversity index, a measure of biodiversity which quantifies how equal the community is numerically. The evenness of a community can be represented by Pielou's evenness index:

The Pielou evenness index (J) applies to the distribution in a group or society of the number of individuals:

$$
\mathrm{J}_{\mathrm{e}}{ }^{\prime}=\frac{H_{e}^{\prime}}{H_{\text {emax }}^{\prime}}
$$

The value of Pielou's evenness lies between 0 (no evenness) and 1 (complete evenness). 


\section{Taxonomic and Phylogenetic Diversity}

For each map, we also estimated the number of species, mean phylogenetic distance (MPD), mean nearest taxon distance (MNTD), and phylogenetic diversity (PD). Over millions of years, PD is the sum of evolutionary history. The average distance between an individual and the most closely connected (nonconspecific) individual is the MNTD. The MNTD in terminal branches is influenced by phylogenetic distance. We compared three PD metrics (PD, MPD, and MNTD) among roads. We selected only these three metrics, because they are the most common and easily differentiated PD metrics.

\section{The Correlation Analysis between Management Variables and Diversity Indices}

We used $\mathrm{R}$ software to analysis the correlation between management variables and diversity indices. Management variables we use as explainery variable and diversity indices were response variable.

\section{Results}

Along wide roads, where the average aboveground biomass was $4.33 \mathrm{~kg} / \mathrm{m}^{2}$, much of the aboveground biomass of trees per unit area was found. The lowest

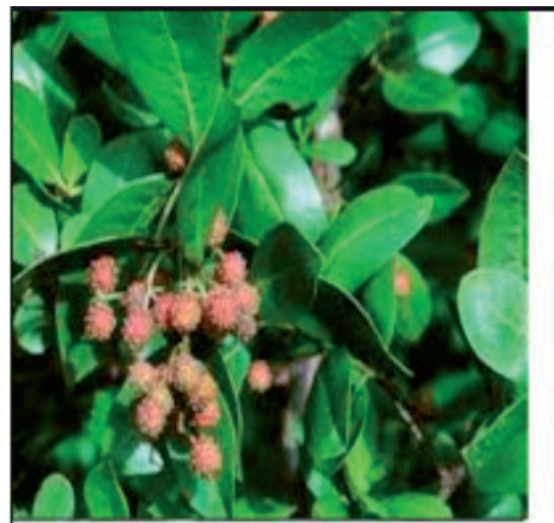

Conocarpus erectus

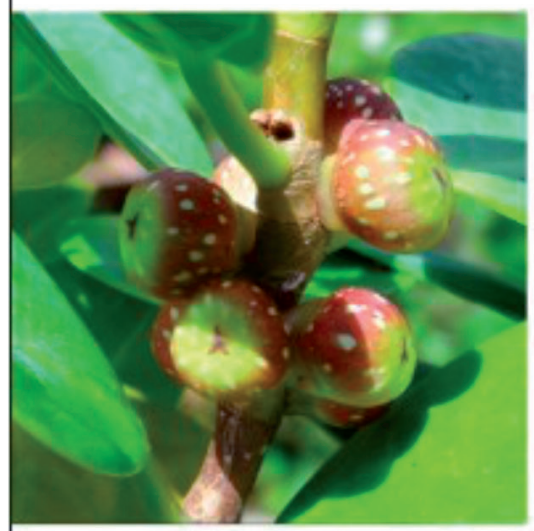

Ficus microcarpa

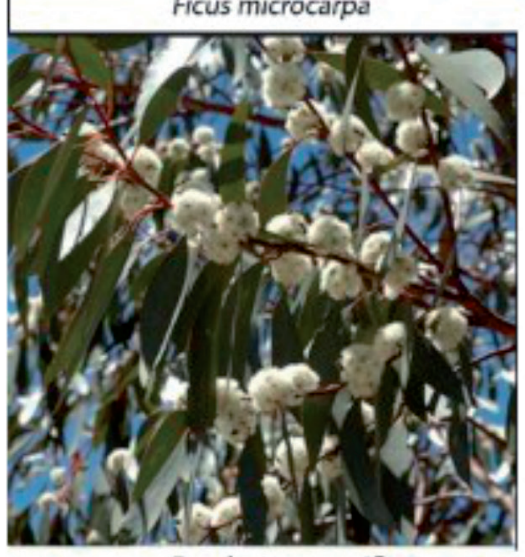

Eucalyptus pauciflora

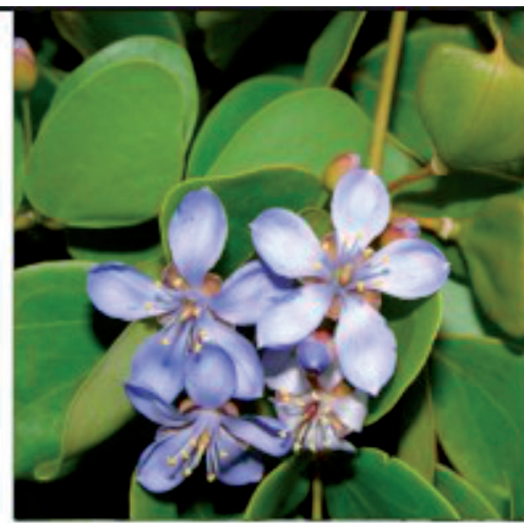

Gualacum officinale

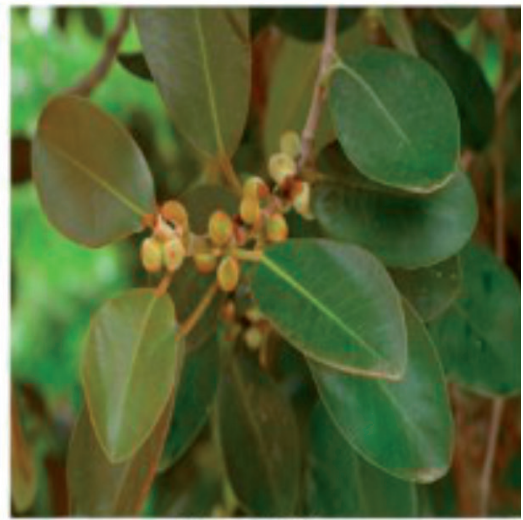

Ficus rubiginosa

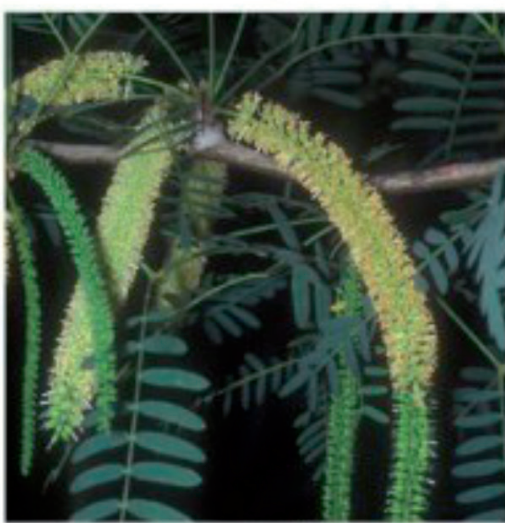

Prosopis juliflora

Fig. 3. Flowers of common non-native trees species in Karachi. 
tree biomass per unit area was $3.20 \mathrm{~kg} / \mathrm{m}^{2}$ along narrow roads. The second-lowest tree biomass per unit area was $3.50 \mathrm{~kg} / \mathrm{m}^{2}$ along medium roads. Moreover, the quantity of aboveground biomass per unit area of roadside trees in the city was significantly different. Overall, lower indices of species richness and diversity were observed. The range of species richness was 4.27-2.44, the range of the Simpson Diversity Index was 0.62-0.32, and the range of Pielou's evenness index was 0.31-0.26. Maximum richness and diversity were observed along wide roads, followed by medium roads and then narrow roads.

Conocarpus erectus had the largest number of trees and was followed by Guaiacum officinale. The native species Azadirachta indica had the largest number of trees, followed by Ficus virens. Overall, 32 non-native and 44 native specimens were found. On all path types, non-native species accounted for $79.16 \%$ and native species accounted for $20.84 \%$ of the tree population. The flowers of common species of non-native trees observed in the region are shown in Fig. 3. The nonnative Conocarpus erectus constituted $61.87 \%$ of the total tree population, and it was followed by Guaiacum officinale with $9.02 \%$. The native Azadirachta indica accounted for $8.51 \%$ of the entire tree population, and it was followed by Ficus virens with $2.47 \%$. The relative distribution of the non-native species was greater than that of the native species in the field under study. Optimum maintenance activities perform in that manner that maximizes benefit avoid abnormal growth with affect traffic. Wide roads and medium roads have optimum maintenance activities (Table 1). Furthermore, 14 indigenous tree species are at high risk (Table 4 and Table 5). High risk means at high level of danger if they were not conserved properly will be disappear soon from the area.

The study found that the PD, MPD and MNTD of non-native tree species were higher than those of native tree species. The PD, MPD and MNTD of wide roads were higher than those of medium and narrow roads for non-native and native tree species (Table 2).Management practices had a significant positive correlation with the indices of diversity (Table 3).

\section{Discussion}

\section{Importance of Roadside Tree Populations}

Different plant species have different patterns of diversity, which results in various growing varieties using roadsides as temporary or permanent habitats. In the last few years, numerous studies have documented how roadsides affect the distribution and dispersal of plant species [29]; however, this study is focused on roadside diversity patterns in a metropolitan city, which attracts attention to diversity patterns in an ecological environment [30]. Results showed the strong superiority of Conocarpus erectus along the roadsides of Karachi, followed by Guaiacum officinale (Tables 4 and 5). The non-native species accounted for $75.16 \%$ and the native species accounted for $24.84 \%$ of the tree communities along all road types. The diversity pattern of the roadside species in Karachi is like the structure of five American municipalities that, at the end of the 1980s, showed significant advantages for single species in their roadside tree communities. Conversely, the prevalence of Conocarpus erectus is more important along all road types since the plant has been grown extensively in the past decade [31]. The typical DBH of Conocarpus erectus is smaller than that of the tree community's native species. Upright trees with a large diameter were not commonly found along urban roads in the research. Conocarpus erectus is also a species with a medium $\mathrm{DBH}$. Trees with a high $\mathrm{DBH}$, recorded on a wide scale,

Table 1. Frequency of roadside tree management variables per year.

\begin{tabular}{|c|c|c|c|c|}
\hline Road types & Trimming & Fertilization & Cleaning & Watering \\
\hline Wide & $5.31 \pm 4.78$ & $3.44 \pm 2.37$ & $99.44 \pm 71.31$ & $99.89 \pm 97.65$ \\
\hline Medium & $4.44 \pm 3.76$ & $2.76 \pm 0.99$ & $103.75 \pm 50.56$ & $101.23 \pm 71.76$ \\
\hline Narrow & $2.09 \pm 0.98$ & $0.79 \pm 0.39$ & $30.61 \pm 19.87$ & $29.98 \pm 19.86$ \\
\hline
\end{tabular}

Table 2. Mean value of PD, MPD and MNTD of three road types in Karachi.

\begin{tabular}{|c|c|c|c|c|c|c|}
\hline Road types & Non-native PD & Native PD & $\begin{array}{c}\text { Non-native } \\
\text { MPD }\end{array}$ & Native MPD & $\begin{array}{c}\text { Non-native } \\
\text { MNTD }\end{array}$ & Native MNTD \\
\hline Wide & $1421.21 \pm 411.33$ & $604.47 \pm 203.57$ & $309.87 \pm 40.31$ & $206.65 \pm 40.64$ & $204.09 \pm 40.15$ & $99.98 \pm 39.87$ \\
\hline Medium & $1178.65 \pm 301.98$ & $501.78 \pm 99.44$ & $204.91 \pm 30.31$ & $99.78 \pm 40.32$ & $99.89 \pm 32.25$ & $99.55 \pm 40.22$ \\
\hline Narrow & $905.78 \pm 201.76$ & $299.98 \pm 104.36$ & $201.21 \pm 29.86$ & $99.89 \pm 29.88$ & $99.87 \pm 29.91$ & $99.95 \pm 19.75$ \\
\hline
\end{tabular}

Note: PD - Faith's phylogenetic diversity; MPD - phylogenetic mean pairwise distance; and MNTD - phylogenetic mean nearest taxon distance 


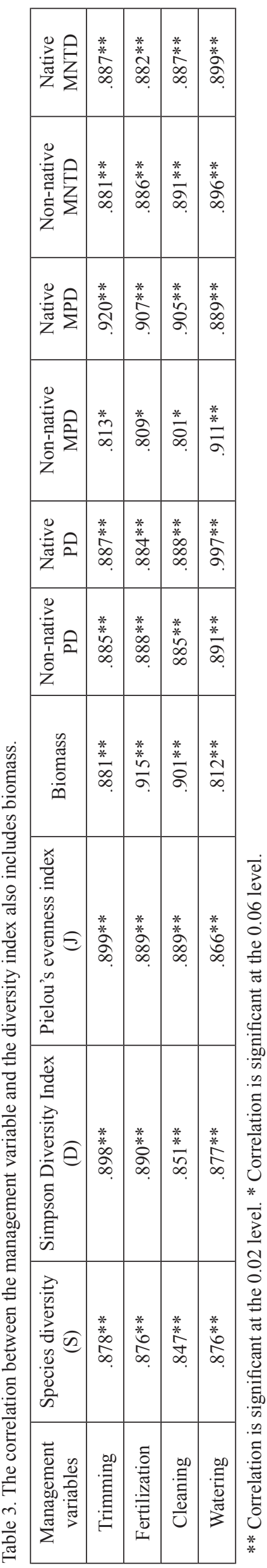

are the major tree species on American urban paths. In comparison, they are much older than those in Karachi.

The tree species diversity of urban forests is a necessary condition for maintaining the stability of urban forests. A high level of tree species diversity helps maintain the stability of urban forests [32]. Tree species diversity is also crucial to the resilience of urban forests. Increasing the level of tree species diversity can enhance the ability of urban forests to resist pests and diseases and climate change. Correspondingly, they have a higher level of tree species diversity [33]. The urban forests in China are more resistant to the disturbances such as extreme weather, pests and diseases. In contrast, the conclusions of many studies have also pointed out that urban vegetation communities with lower levels of diversity are also more susceptible to pests and diseases [34]. The diversity of tree species in urban forests is a necessary condition for maintaining the multiple ecosystem service functions of urban forests. Higher urban tree species diversity can provide richer leisure functions and air purification functions. Residents can also feel a higher sense of happiness from the diverse urban trees, such as harvesting more types of food from them, etc. Social and economic indicators also show human happiness The index and quality of life have been improved with the increase of urban biodiversity [35]. Urban forests with high tree species diversity can continue to provide more diverse and stable ecosystem services. The preference of urban residents for the biodiversity of urban forests is also greater than their expectations for the leisure, entertainment and other uses they can provide. The tree species diversity of urban forests is also an important factor affecting urban biodiversity. First of all, urban forests can help maintain the diversity of tree species, because urban forests themselves can be used as refuges to retain some rare and even endangered species. But at the same time, exotic tree species are passively introduced into urban forests through human planting and management activities. These behaviors result in the replacement of native species by alien species [36]. This replacement process may lead to a decrease in the diversity of native tree species. In addition, urban forests can also maintain the diversity of species in the city by providing food and shelter for wild animals in the urban environment. It also resists disasters caused by waterlogging under the shelter of urban forests. One example of the contribution of tree species diversity to biodiversity is: high level of tree species diversity and relatively stable urban forest systems have high bird diversity.

\section{Variation of Aboveground Tree Biomass in Urban Functional Units}

Our analysis revealed that on large paths, the aboveground tree biomass per unit area significantly exceeded that of other urban functional units. 
Table 4. Number of trees of native species.

\begin{tabular}{|c|c|c|}
\hline Family & Species name & $\begin{array}{c}\text { Number of } \\
\text { trees }\end{array}$ \\
\hline Mimosaceae & Acacia nilotica & 2 \\
\hline Mimosaceae & Acacia Senegal & 2 \\
\hline Primulaceae & Aegiceras corniculata & 2 \\
\hline Rutaceae & Aegle marmelos & 8 \\
\hline Fabaceae & Albizia julibrissin & 505 \\
\hline Fabaceae & Albizia lebbeck & 211 \\
\hline Apocynaceae & Alstonia scholaris & 303 \\
\hline Meliaceae & Azadirachta indica & 3941 \\
\hline Malvaceae & Bombax ceiba & 19 \\
\hline Capparidaceae & Capparis decidua & 2 \\
\hline Fabaceae & Cassia fistula & 69 \\
\hline Malvaceae & Ceiba pentandra & 19 \\
\hline Arecaceae & Cocos nucifera & 409 \\
\hline Boraginaceae & Cordia gharaf & 20 \\
\hline Boraginaceae & Cordia macheodii & 8 \\
\hline Boraginaceae & Cordia myxa & 71 \\
\hline Capparaceae & Crateva adansonii & 205 \\
\hline Fabaceae & Dalbergia sissoo & 19 \\
\hline Poaceae & Dendrocalamus stricta & 409 \\
\hline Fabaceae & Erythrina suberosa & 92 \\
\hline Euphorbiaceae & Euphorbia caducifolia & 2 \\
\hline Euphorbiaceae & Euphorbia tirucalli & 2 \\
\hline Moraceae & Ficus amplissima & 35 \\
\hline
\end{tabular}

This suggests that the density of species is high or the number of trees on wide roads per unit area is significant. The greening rate of this region is one explanation for the fluctuations in tree biomass along large roads. Via land-use adjustments, the trees used for natural resources will be preserved, and this positive pattern has been seen in many places.

The tree species that are difficult to adapt to the local climate are often unable to survive in the city for a long time on the scale of the scale (although studies have also shown that) Man-made management, such as the use of microclimates, irrigation and other means, can reduce the impact of climate to a certain extent, but their distribution range is still impossible on the scale of the entire urban forest. Avoid being restricted by climatic conditions. Among them, the limiting effect of low temperature is very obvious. Extreme low temperature events affect the distribution range of plants by determining the survival of plants. The topography (aspect, slope, etc.) indirectly affects the distribution of urban tree species through the influence

\begin{tabular}{|c|c|c|}
\hline Family & Species name & $\begin{array}{c}\text { Number of } \\
\text { trees }\end{array}$ \\
\hline Moraceae & Ficus benghalensis & 307 \\
\hline Moraceae & Ficus racemosa & 97 \\
\hline Moraceae & Ficus religiosa & 398 \\
\hline Moraceae & Ficus rumphii & 32 \\
\hline Moraceae & Ficus virens & 999 \\
\hline Meliaceae & Melia azedarach & 201 \\
\hline Mimosaceae & Mimosa hamata & 2 \\
\hline Moringaceae & Moringa oleifera & 302 \\
\hline Palmae & Nannorphs ritichiana & 2 \\
\hline Arecaceae & Phoenix dactylifera & 601 \\
\hline Mimosaceae & Prosopis cineraria & 2 \\
\hline Lythraceae & Punica granutum & 9 \\
\hline Salvadoraceae & Salvadora oleoides & 2 \\
\hline Salvadoraceae & Salvadora persica & 2 \\
\hline Tamaricaceae & Tamarix aphylla & 2 \\
\hline Bignoniaceae & Tecomella undulata & 2 \\
\hline Combretaceae & Terminalia catappa & 187 \\
\hline Malvaceae & Thespesia pupulnea & 99 \\
\hline Rhamnaceae & Ziziphus jujuba & 299 \\
\hline Rhamnaceae & Ziziphus mauritiana & 175 \\
\hline \multirow[t]{2}{*}{ Rhamnaceae } & Zizyphus nummularia & 2 \\
\hline & 38643 & 9632 \\
\hline
\end{tabular}

of factors such as light and temperature [37]. The salt and alkali components in the soil also have an important impact on the distribution of tree species through longterm stress on urban tree species. This also explains to some extent the phenomenon that the species pools around cities often show high similarities with urban tree species.

The urban environment is another important factor affecting the distribution of urban tree species. In the case of small and medium-sized urban habitat changes, urban tree species can survive 38-90\% wider than their natural distribution range. On the other hand, numerous studies have also pointed out that the urban microclimate environment, pollution and other stresses can have a negative impact on the long-term survival of tree species in the city.

With the division of different functional areas in cities, land use has also become a major factor in shaping the pattern of urban tree species diversity. In rapidly urbanizing areas, the current land use types play a leading role in the diversity of urban tree species. 
Table 5. Number of trees of non-native species.

\begin{tabular}{|c|c|c|}
\hline Family & Species name & $\begin{array}{c}\text { Number of } \\
\text { trees }\end{array}$ \\
\hline Araucariaceae & Araucaria cunninghamii & 6 \\
\hline Caricaceae & Carica papaya & 8 \\
\hline Fabaceae & Cassia siamea & 88 \\
\hline Casuarinaceae & Casuarina equisetifolia & 61 \\
\hline Combretaceae & Conocarpus erectus & 28475 \\
\hline Boraginaceae & Cordia sebestena & 14 \\
\hline Fabaceae & Delonix regia & 31 \\
\hline Myrtaceae & Eucalyptus pauciflora & 1816 \\
\hline Bignoniaceae & Fernandoa adenophylla & 19 \\
\hline Moraceae & Ficus benjamina & 48 \\
\hline Moraceae & Ficus elastica & 78 \\
\hline Moraceae & Ficus lyrata & 6 \\
\hline Moraceae & Ficus microcarpa & 498 \\
\hline Moraceae & Ficus rubiginosa & 404 \\
\hline Zygophylaceae & Guaiacum officinale & 5249 \\
\hline Fabaceae & Leucaena leucocephala & 204 \\
\hline Arecaceae & Livistona chinensis & 33 \\
\hline Anacardiaceae & Mangifera indica & 40 \\
\hline Sapotaceae & Manilkara zapota & 7 \\
\hline Bignoniaceae & Millingtonia hortensis & 21 \\
\hline Moraceae & Morus nigra & 21 \\
\hline Apocynaceae & Nerium oleander & 9 \\
\hline Fabaceae & Parkinsonia aculeata & 93 \\
\hline Fabaceae & Peltophorum pterocarpum & 91 \\
\hline Fabaceae & Pithecellobium dulce & 74 \\
\hline Annonaceae & Polyalthia longifolia & 76 \\
\hline Fabaceae & Prosopis juliflora & 301 \\
\hline Arecaceae & Roystonea regia & 89 \\
\hline Myrtaceae & Syzgium cumini & 38 \\
\hline Bignoniaceae & Tabebuia heterophylla & 65 \\
\hline Fabaceae & Tamarindus indica & 32 \\
\hline Arecaceae & Washingtonia robusta & 6 \\
\hline
\end{tabular}

The tree types on different land uses change with the change of land use types, but in some areas these tree species It also shows a legacy effect, that is, despite the conversion of land use, the previous tree species and functional characteristics can still be retained. For example, in Haikou City, some Casuarina equisetifolia grow in residential areas and idle land converted from forest land, but Casuarina equisetifolia itself is not a tree for gardens and landscapes. They were only used as tree species for coastal protection forest construction in the 1960s and 1970s. It was introduced to Haikou. This also confirms to a certain extent that a previous study using Guangzhou as an example-legacy effects can affect the diversity of urban tree species. Human factors will also have an important impact on the diversity of urban tree species, which is mainly reflected in the impact of green management policies and human preferences on urban tree species diversity. In the process of urbanization, those tree species that have no direct economic or social value to human beings are most vulnerable to threats. They are usually easily removed in the process of land use conversion [38]. For example, the preserved trees in the urbanization process of Haikou are mostly fruit trees. This phenomenon of fruit trees being easily preserved consciously in the process of urbanization has also been observed in the study of Shanghai. Research on Guangzhou City also found that urban residents are more concerned about the aesthetic and economic value of greening tree species [39]. And those trees that cannot make residents or developers perceive value, even rare tree species or even endangered species, are unlikely to be preserved in the process of land use conversion. The preference of urban residents for the selection of urban plant species is also reflected in the difference in education level and income level [40]. On the one hand, the reason may be due to human preference (like the trees themselves), on the other hand, they may also be limited by the supply of nursery stocks at that time. However, these studies did not quantify the impact of human factors on urban tree species.

\section{Conclusion}

To assess the taxonomic and phylogenetic richness of roadside trees in Karachi, the capital of Sindh province, we utilized a variety of approaches. In our study site, the richness and composition of plants were significantly affected by road types. Results show that diversity is positively correlated with road width is accepted. The importance of plant diversity has many influencing factors:

- Pay attention to plant diversity. The singularity of plant species has resulted in the same pattern of urban landscaping in my country, without its own style and characteristics; the single color of plants makes people feel very boring; the single function of plants is the result of lack of humane consideration in planning and design; single use of space, resulting in a waste of resources.

- The layout is reasonable, sparse and coherent, singlegroup combination. Plants in nature are not all grouped, but also solitary. There are many ways to configure garden plants, such as solitary planting, row planting, patch planting, group planting, and mixed planting. The beauty of the tree planting. 
- Pay attention to the reasonable collocation of the shapes and colors of different garden plants. The arrangement of garden plants should be based on plants of different shapes and colors according to the topography and landforms, and they should not conflict with each other in perspective, nor can they conflict with other garden buildings and garden sketches in perspective.

- Pay attention to the integration of the cultural nature of garden plants with the surrounding environment. While the garden plant configuration is based on ecological principles, it should also be combined with aesthetic principles. But it should be ecology first, then landscape, in other words, letting nature take place is the prerequisite, rather than subordination to nature.

\section{Conflict of Interest}

The authors declare no conflict of interest.

\section{References}

1. ARONSON M.F., LEPCZYK C.A., EANS K.L., GODDARD M.A., LERMAN S.B., MACLVOR J.S., VaARGO T. Biodiversity in the city: key challenges for urban green space management. Frontiers in Ecology and the Environment, 15 (4), 189, 2017.

2. HADLEY A.S., BETTS M.G. The effects of landscape fragmentation on pollination dynamics: absence of evidence not evidence of absence. Biological Reviews, 87 (3), 526, 2012.

3. YILMAZ H., YILMA Z. Use of native plants in landscape planning of roadside banks under extreme climatic conditions in eastern Anatolia, Turkey. International Journal of Biodiversity Science \& Management, 5 (2), 102, H. 2009.

4. THOMPSON G.L., KAO-KNIFFIN J. Applying biodiversity and ecosystem function theory to turfgrass management. Crop Science, 57 (S1), S, 2017.

5. CUMMING G., PETERSON G. Ecology in global scenarios. Ecosystems and human well-being: scenarios, 2, 45, 2005.

6. JIM C.Y., CHEN W.Y. Ecosystem services and valuation of urban forests in China. Cities, 26 (4), 187, 2009.

7. CHEN W.Y., JIM C.Y. Assessment and valuation of the ecosystem services provided by urban forests. Ecology, planning, and management of urban forests, 53, 2008.

8. HIROKAWA K.H. Sustainability and the urban forest: An ecosystem services perspective. Natural Resources Journal, 233, 2011.

9. MANNING W.J. Plants in urban ecosystems: Essential role of urban forests in urban metabolism and succession toward sustainability. The International Journal of Sustainable Development \& World Ecology, 15 (4), 362, 2008.

10. FRIESS D.A. Singapore as a long-term case study for tropical urban ecosystem services. Urban ecosystems, 20 (2), 277, 2017.

11. PICKETT S.T., CADENASSO M.L., GROVE J.M., BOONE C.G., GROFFMAN P.M., IRWIN E., WARREN P.
Urban ecological systems: Scientific foundations and a decade of progress. Journal of environmental management, 92 (3), 331, 2011.

12. GONZALEZ DEL TANAGO M., GARCIA DE JALON D. Riparian Quality Index (RQI): A methodology for characterising and assessing the environmental conditions of riparian zones. Limnetica, 30 (2), 0235, 2011.

13. NG E., CHEN L., WANG Y., YUAN C. A study on the cooling effects of greening in a high-density city: An experience from Hong Kong. Building and environment, 47, 256, 2012.

14. RATCLIFFE D.A. Post-medieval and recent changes in British vegetation: the culmination of human influence. New Phytologist, 98 (1), 73, 1984.

15. VELLEND M., BAETEN L., BECKER-SAVRPITTA A., BOUCHER-LALONDE V., MCCUNE J.L., MESSIER J., SAX D. F. Plant biodiversity change across scales during the Anthropocene. Annual Review of Plant Biology, 68, 563, 2017.

16. KAREIVA P., WATTS S., MCDONALD R., BOUCHER T. Domesticated nature: shaping landscapes and ecosystems for human welfare. Science, 316 (5833), 1866, 2007.

17. HANSEN A.J., RASKER R., MAXWELL B., TOTELLA J.J., JOHNSON J.D., PARMENTER A.W., KRASKA M.P. Ecological Causes and Consequences of Demographic Change in the New West: As natural amenities attract people and commerce to the rural west, the resulting landuse changes threaten biodiversity, even in protected areas, and challenge efforts to sustain local communities and ecosystems. BioScience, 52 (2), 151, 2002.

18. KONG F., YIN H., NAKAGOSHI N. Using GIS and landscape metrics in the hedonic price modeling of the amenity value of urban green space: A case study in Jinan City, China. Landscape and urban planning, 79 (3-4), 240, 2007.

19. LUO P., SONG Y., WU P. Spatial disparities in tradeoffs: economic and environmental impacts of road infrastructure on continental level. GIScience \& Remote Sensing, 1, 2021.

20. BESTELMEYER B.T., WIENS J.A. Ant biodiversity in semiarid landscape mosaics: the consequences of grazing vs. natural heterogeneity. Ecological Applications, 11 (4), 1123, 2001.

21. WINTER M., DEVICTOR V., SCHWEIGER O. Phylogenetic diversity and nature conservation: where are we?. Trends in ecology \& evolution, 28 (4), 199, 2013.

22. KELLAR P.R., AHRENDSEN D.L., AUST S.K., JONES A.R., PIRES J.C. Biodiversity comparison among phylogenetic diversity metrics and between three North American prairies. Applications in Plant Sciences, 3 (7), 1400108, 2015.

23. MIDDEN C.J., KAISER F.G., TEDDY MCCALLEY L. Technology's four roles in understanding individuals' conservation of natural resources. Journal of Social Issues, 63 (1), 155, 2007.

24. PEDEN, MARGIE, SCURFIELD R., SLEET D., MATHERS C., JARAWAN E., HYDER A.A., HYDER A.A., MOHAN D., JARAWAN E. World report on road traffic injury prevention. World Health Organization, 2004.

25. BARBER J.R., BURDETT C.L., REED S.E., WARNER K.A., FORMICHELLA C., CROOKS K.R., FRISTRUP K.M. Anthropogenic noise exposure in protected natural areas: estimating the scale of ecological consequences. Landscape ecology, 26 (9), 1281, 2011.

26. QURESHI S., KAZMI S.J.H., BREUSTE J.H. Ecological disturbances due to high cutback in the green 
infrastructure of Karachi: analyses of public perception about associated health problems. Urban Forestry \& Urban Greening, 9 (3), 187, 2010.

27. BARWISE Y., KUMAR P. Designing vegetation barriers for urban air pollution abatement: a practical review for appropriate plant species selection. Npj Climate and Atmospheric Science, 3 (1), 1, 2020.

28. BUKHARI M.H., SAYAL E.A. Emerging climate changes and water resource situation in Pakistan. Pakistan Vision, 12 (2), 236, 2011.

29. LINHART Y.B., GRANT M.C. Evolutionary significance of local genetic differentiation in plants. Annual review of ecology and systematics, 27 (1), 237, 1996.

30. ALTIERI M.A., LETOURNEAU D.K., RISCH S.J. Vegetation diversity and insect pest outbreaks. Critical Reviews in Plant Sciences, 2 (2), 131, 1984.

31. NAIK B., MATLACK G., KHOURY I., SINHA G., MCAVOY D.S. Effects of tree canopy on rural highway pavement condition, safety, and maintenance (No. FHWA/ OH-2017/18). Ohio Research Institute for Transportation and the Environment, 2017.

32. BHATTI U.A., YUAN L., YU Z., NAWAZ S.A., MEHMOOD A., BHATTI M.A., XIAO S. Predictive Data Modeling Using sp-kNN for Risk Factor Evaluation in Urban Demographical Healthcare Data. Journal of Medical Imaging and Health Informatics, 11 (1), 7, 2021.

33. ORDONEZ C., DUINKER P.N. Ecological integrity in urban forests. Urban Ecosystems, 15 (4), 863, 2012.

34. ESCOBEDO F.J., CLERICI N., STAUDHAMMER C.L., CORZO G.T. Socio-ecological dynamics and inequality in Bogotá, Colombia's public urban forests and their ecosystem services. Urban Forestry \& Urban Greening, 14 (4), 1040, 2015.

35. BUDDE K.B., NIELSEN L.R., RAVN H.P., KKAER E. D. The natural evolutionary potential of tree populations to cope with newly introduced pests and pathogens-lessons learned from forest health catastrophes in recent decades. Current Forestry Reports, 2 (1), 18, 2016.

36. BRASIER C.M. The biosecurity threat to the UK and global environment from international trade in plants. Plant Pathology, 57 (5), 792, 2008.

37. TAN P.Y., BIN ABDUL HAMID A.R. Urban ecological research in Singapore and its relevance to the advancement of urban ecology and sustainability. Landscape and Urban Planning, 125, 271, 2014.

38. COUTTS A.M., TAPPER N.J., BERINGER J., LOUGHNAN M., DEMUZERE M. Watering our cities: The capacity for Water Sensitive Urban Design to support urban cooling and improve human thermal comfort in the Australian context. Progress in physical geography, 37 (1), $2,2013$.

39. MCINTYRE N.E., RANGO J., FAGAN W.F., FAETH S.H. Ground arthropod community structure in a heterogeneous urban environment. Landscape and urban planning, 52 (4), 257, 2001.

40. DADASHPOOR H., AZIZI P., MOGHADASI M. Land use change, urbanization, and change in landscape pattern in a metropolitan area. Science of the Total Environment, 655, 707, 2019.

41. JONES G., CREGG B., SCHNELLER1 K. True Firs (Abies sp.): New conifers for the Midwestern landscape. HortScience, 39 (4), 897C, 2004. 